\title{
Zero Emission Power Plants Using Solid Oxide Fuel Cells and Oxygen Transport Membranes
}

\author{
Final Report
}

Reporting Period Start Date July 12, 2000

Reporting Period End DateMarch 31, 2003

Principal Authors

G. Maxwell Christie Praxair

Troy M. Raybold Praxair

Contributing Authors

Edzard Luebben SWPC

Keqin Huang SWPC

Report issued on June 10,2003

DOE award number DE-FC26-00NT 40795

Submitting Organization

Siemens Westinghouse Power Corporation

1310 Beulah Road

Pittsburgh, PA 15235

$\underline{\text { Subcontractor }}$

Praxair, Inc

175 East Park Drive

Tonawanda, NY 14150 


\section{DISCLAIMER}

This report was prepared as an account of work sponsored by an agency of the United States Government. Neither the United States Government nor any agency thereof, nor any of their employees, makes any warranty, express or implied, or assumes any legal liability or responsibility for the accuracy, completeness, or usefulness of any information, apparatus, product, or process disclosed, or represents that its use would not infringe privately owned rights. Reference herein to any specific commercial product, process, or service by trade name, trademark, manufacturer, or otherwise does not necessarily constitute or imply its endorsement, recommendation, or favoring by the United States Government or any agency thereof. The views and opinions of authors expressed herein do not necessarily state or reflect those of the United States Government or any agency thereof.

\section{ABSTRACT}

Over 16,700 hours of operational experience was gained for the Oxygen Transport Membrane (OTM) elements of the proposed SOFC/OTM zero-emission power generation concept. It was repeatedly demonstrated that OTMs with no additional oxidation catalysts were able to completely oxidize the remaining depleted fuel in a simulated SOFC anode exhaust at an $\mathrm{O}_{2}$ flux that met initial targets. In such cases, neither residual $\mathrm{CO}$ nor $\mathrm{H}_{2}$ were detected to the limits of the gas chromatograph $(<10$ ppm). Dried OTM afterburner exhaust streams contained up to $99.5 \% \mathrm{CO}_{2}$. Oxygen flux through modified OTMs was double or even triple that of the standard OTMs used for the majority of testing purposes. Both the standard and modified membranes in laboratory-scale and demonstration-sized formats exhibited stable performance over extended periods (2300 to 3500 hours or 3 to 5 months). Reactor contaminants, , were determined to negatively impact OTM performance stability. A method of preventing OTM performance degradation was developed and proven to be effective. Information concerning OTM and seal reliability over extended periods and through various chemical and thermal shocks and cycles was also obtained. These findings were used to develop several conceptual designs for pilot (10 kWe) and commercial-scale (250 kWe) SOFC/OTM zero emission power generation systems. 


\section{TABLE OF CONTENTS}

ABSTRACT

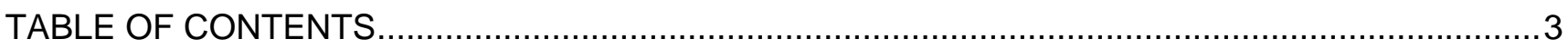

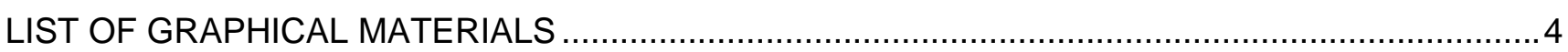

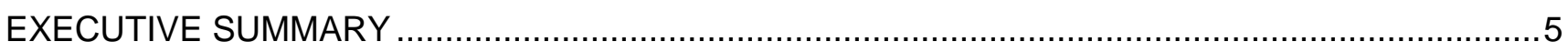

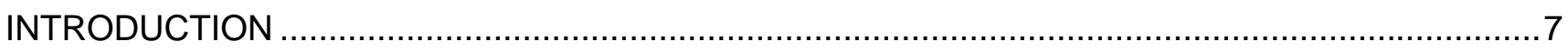

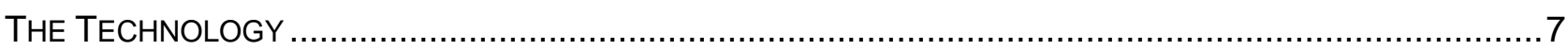

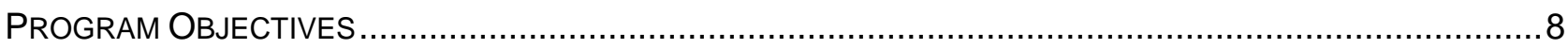

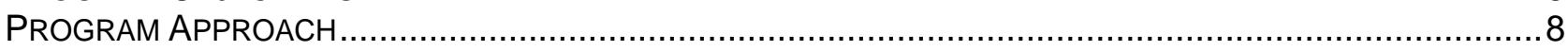

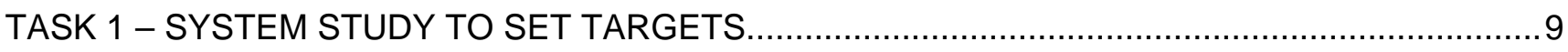

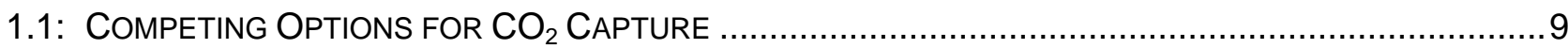

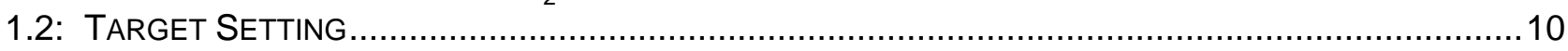

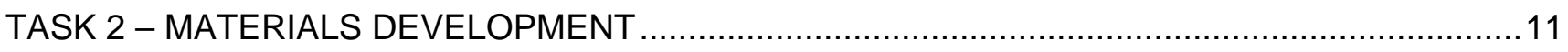

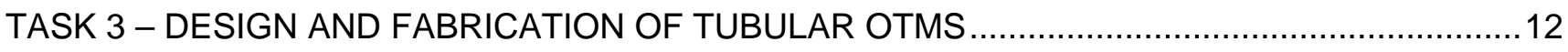

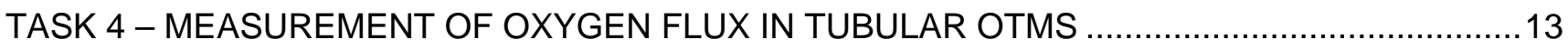

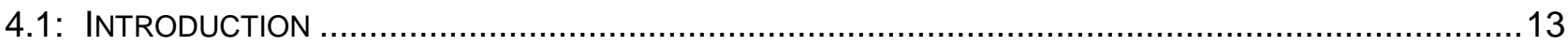

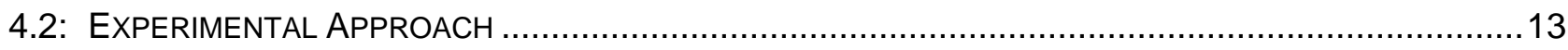

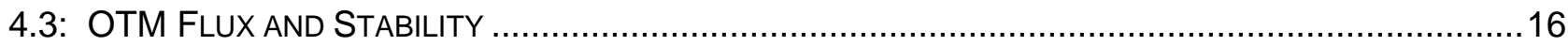

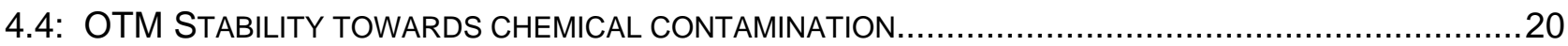

4.4.1: High temperature metals................................................................................................................ 20

4.4.2: High temperature insulation ............................................................................................................ 22

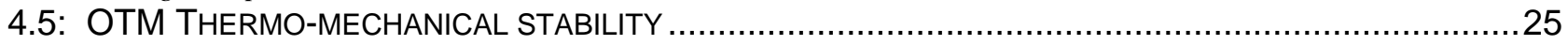

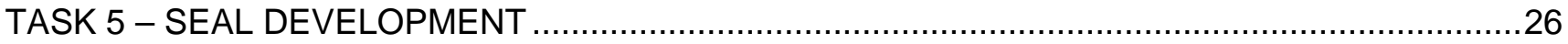

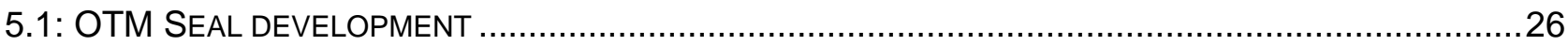

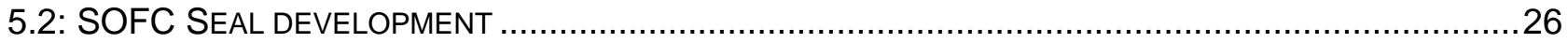

TASK 6 - CONCEPTUAL DESIGN OF THE SOFC AND OTM MODULE(S) …..............................27

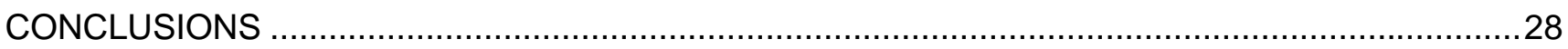

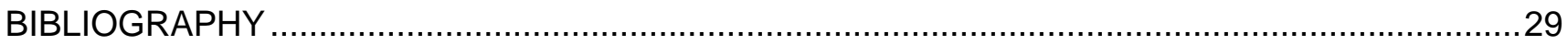




\section{LIST OF GRAPHICAL MATERIALS}

FIGURE 1: PRINCIPLE OF OTM AFTERBURNER OPERATION ……......................................

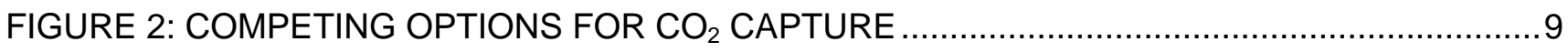

FIGURE 3: PHOTOGRAPH OF AS MANUFACTURED, DEMONSTRATION-SIZED TUBULAR

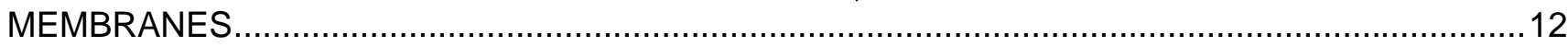

FIGURE 4: PHOTOGRAPHS OF THE LABORATORY-SCALE AND DEMONSTRATION-SIZED,

SINGLE TUBE OTM REACTORS AT PRAXAIR AND SWPC

FIGURE 5: SCHEMATIC OF THE PRAXAIR LABORATORY-SCALE, SINGLE TUBE OTM REACTOR

FIGURE 6: SCHEMATIC OF THE SWPC DEMONSTRATION-SIZED, SINGLE-TUBE, OTM REACTOR

FIGURE 7: COMPARISON OF STANDARD OTM VERSUS MODIFIED OTM FLUX AS

PERCENTAGE OF TARGET

FIGURE 8: LEAK-CORRECTED AVERAGE O 2 FLUX (TOP) AND DRIED AFTERBURNER EXHAUST COMPOSITION (BOTTOM) OVER THE 3500 HRS. TESTING OF A LABORATORYSIZED, UN-MODIFIED OTM AT PRAXAIR.

FIGURE 9: LEAK-CORRECTED AVERAGE O ${ }_{2}$ FLUX (TOP) AND DRIED AFTERBURNER EXHAUST COMPOSITION (BOTTOM) OVER THE 2300 HRS. OF TESTING A DEMONSTRATIONSIZED, UNMODIFIED OTM AT SWPC.

FIGURE 10: LEAK-CORRECTED AVERAGE $\mathrm{O}_{2}$ FLUX OVER THE 2500 HRS. OF TESTING A MODIFIED, HIGH-FLUX, DEMONSTRATION-SIZED OTM AT SWPC.

FIGURE 11: LEAK-CORRECTED AVERAGE OXYGEN FLUX AS A FUNCTION OF TIME WHEN USING A 'REACTOR ALLOY A' AIR-FEED TUBE IN A LABORATORY-SCALE, OTM TEST AT PRAXAIR.

FIGURE 12: SCANNING ELECTRON MICROGRAPH SHOWING A CROSS-SECTION OF THE 'REACTOR ALLOY A' AIR-FEED TUBE FOLLOWING THE 700 HOUR OTM TEST.

FIGURE 13: SCHEMATIC OF THE MODIFIED LABORATORY-SCALE OTM REACTOR AT PRAXAIR TO FACILITATE $\mathrm{SIO}_{2}$-BASED OTM CONTAMINATION TESTING.

FIGURE 14: PLOTS OF BASE-CASE SIO 2 DEGRADATION VS. OXYGEN FLUX STABILITY WHEN A MEANS TO PREVENT THE OTM DEGRADATION DUE TO TRANSPORTED $\mathrm{SIO}_{2}$ WAS INCLUDED IN A LABORATORY-SCALE, OTM TEST AT PRAXAIR.

FIGURE 15: DRIED AFTERBURNER EFFLUENT COMPOSITION OVER THE 850 HRS.OF TESTING OF A LABORATORY-SIZED, OTM AT PRAXAIR. THE EXPERIMENT INCLUDES A $\mathrm{SIO}_{2}$ SOURCE AND A MEANS TO PREVENT OTM DEGRADATION. 


\section{EXECUTIVE SUMMARY}

In the Solid Oxide Fuel Cell (SOFC) power generation systems developed by Siemens Westinghouse Power Corporation (SWPC), the anode exhaust of depleted fuel is combined and reacted with the cathode exhaust of vitiated air. This results in an exhaust stream containing $\mathrm{CO}_{2}$ diluted by a substantial quantity of $\mathrm{N}_{2}$ and $\mathrm{O}_{2}$. Dilution makes the separation and sequestration of the $\mathrm{CO}_{2}$ from the stream less attractive economically. SWPC is developing a fluid seal concept in which steam is used to buffer (separate) the anode and cathode exhausts. By employing such a seal, the separated, depleted fuel from the SOFC anode exhaust can be post-combusted in a relatively pure $\mathrm{O}_{2}$ stream to yield a pure, and therefore more economically viable, sequesterable stream of $\mathrm{CO}_{2}$ upon drying.

This project set out to determine the technical and economic feasibility of using Praxair's Oxygen Transport Membrane (OTM) technology to post-combust the residual fuel of a separated SOFC anode exhaust in pure $\mathrm{O}_{2}$. The tasks carried out during the course of the project including a system study, materials development, OTM fabrication, OTM testing, OTM seal development and conceptual design of the SOFC/OTM modules.

Two laboratory-scale membrane test stands were designed and commissioned at Praxair. An existing SOFC test stand at SWPC was modified to accommodate the demonstration-sized membranes. Throughout the project, it was repeatedly demonstrated, on both laboratory-scale and demonstrationsized OTMs, that depleted fuel exiting the SOFC could be completely oxidized without the need for additional catalysts. Sequesterable streams were produced, with typical dried OTM exhaust compositions of $97-99.5 \% \mathrm{CO}_{2}, 0-2 \% \mathrm{O}_{2}$, and $0-1 \% \mathrm{~N}_{2}$. The OTM flux targets for the application were achieved.

Several long-term performance stability tests were conducted in order to gauge the stability of the OTMs in the high concentrations of $\mathrm{CO}_{2} \& \mathrm{H}_{2} \mathrm{O}$ present in the SOFC anode exhaust. Tests at Praxair focused on laboratory-scale OTMs, while SWPC modified an existing reactor to accommodate demonstration-sized OTMs. A laboratory-scale OTM at Praxair exhibited a stable flux for around 3500 hours (5 months) before the experiment was shut-down. A demonstration-sized OTM, tested at SWPC exhibited a stable flux for over 2300 hours (3 months). No evidence of corrosion or loss of performance of the OTM membranes were observed in either test.

Performance stability was satisfactory in the relatively inert environments of the reactor simulations. It is known that in high temperature systems, Cr-species can be volatilized from the high temperature alloys used to construct the reactors and gas-phase Si-species are formed when steam-containing process streams wet the surface of high temperature insulation materials. It was anticipated that these contaminants would be present in the process streams of commercial OTM afterburner systems. A series of experiments were designed in order to evaluate the stability of the selected OTM materials when these contaminants were introduced into the process streams.

In one series of experiments, Si-sources, in the form of high temperature insulation materials, were placed upstream of the membranes in the laboratory-scale reactors at Praxair. It was established that $\mathrm{Si}$, transported in the form of a volatilized, vapor-phase species could rapidly and catastrophically degrade the OTM membrane performance. Various means to prevent the degradation were devised and tested.

In addressing the problems of Cr-contamination, Praxair surveyed the availability, strength, creepresistance and workability of the known $\mathrm{Al}_{2} \mathrm{O}_{3}$ scale forming high temperature alloys. One alloy, designated reactor alloy $\mathrm{A}$, was selected for further investigation. The alloy was selected primarily on the basis of availability in tube, sheet and bar stock form, pending a near-term demonstration of the 
technology. In a laboratory-scale membrane test at Praxair, a pre-oxidized, reactor alloy A tube was used to feed air at high temperatures $\left(1000^{\circ} \mathrm{C}\right)$ to the OTM membrane. Some deterioration in the oxygen flux through the membrane was observed during the 700 -hour test but the degradation was not catastrophic.

Robustness and resistance of the OTMs to thermal cycles and chemical shock needs also to be evaluated before considering a demonstration project. In a practical system, the OTMs would have to survive any change in the temperature or composition of the anode exhaust gas exiting the SOFC. Both laboratory-scale and demonstration-sized membranes were intentionally subjected to such shocks. To simulate a no-load (open-circuit) situation for the SOFC, the typical fuel slate was quickly replaced by a stream with more concentrated fuels. Rapid heating and cooling and rapid introduction or removal of air and fuel streams to the OTM was also evaluated in order to simulate quick startups and shutdowns. Although the OTM membranes repeatedly survived many of the thermal cycles and chemical shocks, the selected OTM material did not survive all of the imposed conditions.

Praxair and SWPC jointly developed a preliminary design for a pilot-scale $10 \mathrm{kWe}$ SOFC/OTM zero emission technology demonstration. A commercial-scale system based on a $250 \mathrm{kWe}$ SOFC was also conceptualized. For initial demonstrations of the technology, Praxair and SWPC agreed that the SOFC and the OTM would be separate close-coupled modules, as separate modules provide more flexibility in designing strategies to facilitate startup, shutdown and transient operation of the system. Desirable developments to aid in improving future OTM afterburner modules would include greater OTM and seal tolerance for various startup, shutdown and transient schemes, as well as increased OTM resistance to reactor contaminants. 


\section{INTRODUCTION}

\section{The Technology}

The primary goal of the Vision 21 program is to develop technology that enables zero emission power generation systems. A $250 \mathrm{kWe}$, Siemens-Westinghouse SOFC operating at $47 \%$ efficiency LHV emits $\sim 1.2 \mathrm{lbs} \mathrm{CO}_{2} / \mathrm{kWh}$. The SOFC modules demonstrated by SWPC to date have combined and combusted the anode exhaust of depleted fuel with the cathode exhaust of vitiated air. On drying, the result is a SOFC exhaust stream containing $\mathrm{CO}_{2}$ diluted by a substantial quantity of $\mathrm{N}_{2}$ and $\mathrm{O}_{2}$.

Separation of the $\mathrm{CO}_{2}$ for subsequent sequestration is economically challenging.

SWPC is developing steam-based fluid seal technology to separate the SOFC anode and cathode streams, while Praxair is developing OTM technology to separate oxygen from air. Integration of the two technologies facilitates post-combustion of residual fuel from the SOFC in oxygen, with the result being a power generation system with an exhaust stream containing only $\mathrm{H}_{2} \mathrm{O}$ and $\mathrm{CO}_{2}$.

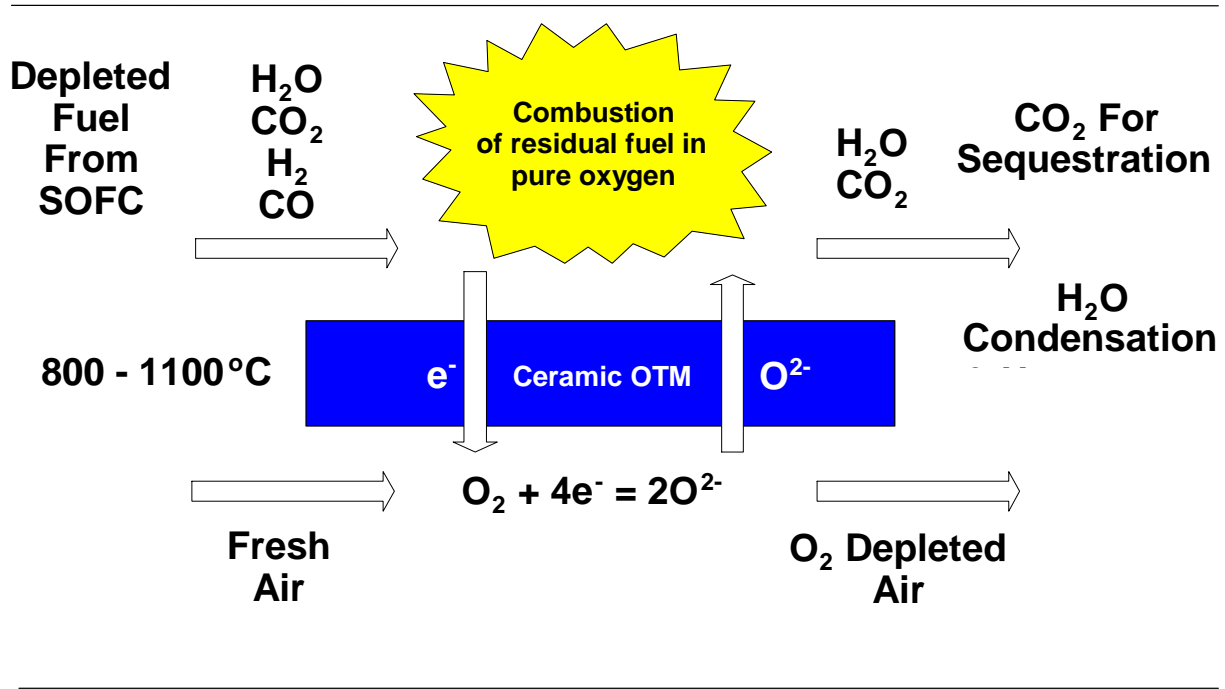

\section{Figure 1: Principle of OTM afterburner operation}

As shown in Figure 1, the exhaust stream of the SOFC is directed to one side of an OTM and air is fed to the opposite side of the dense, gas tight membrane. Pure oxygen is transported as $\mathrm{O}^{2-}$ ions through the dense wall of ceramic and oxidizes the residual $\mathrm{CO}$ and $\mathrm{H}_{2}$ remaining in the SOFC exhaust. 


\section{Program Objectives}

The primary objective of the program was to develop a conceptual design for a SOFC/OTM zero emission power generation system and to assess the technical and economic viability of the concept.

Praxair and SWPC collaborated in:

- Setting oxygen flux targets for the OTM materials

- Selecting and characterizing OTM materials

- Designing and fabricating the OTM elements

- Evaluating the OTM oxygen flux and stability in small scale reactors

- Developing seals, both for the OTM elements and in order to separate the SOFC anode and cathode exhaust streams

- Developing conceptual designs for the OTM module

- Developing start-up and shut-down protocols for the OTM module

\section{Program Approach}

The technical work program was divided into the six separate tasks listed below.

TASK 1 - System Study to Set Targets

TASK 2 - Materials Development

TASK 3 - Design and Fabrication of Tubular OTMs

TASK 4 - Measurement of Oxygen Flux in Tubular OTMs

TASK 5 - Seal Development

TASK 6 - Conceptual Design of SOFC and OTM modules

This report summarizes progress made against each of the above tasks. 


\section{TASK 1 - SYSTEM STUDY TO SET TARGETS}

\section{1: Competing Options for $\mathrm{CO}_{2}$ Capture}

In order to estimate the economic value of $\mathrm{CO}_{2}$ capture two approaches can be taken. One is to consider the current and expected future $\mathrm{CO}_{2}$ taxes or $\mathrm{CO}_{2}$ trading values in countries where $\mathrm{CO}_{2}$ is already traded or taxed. The other is to undertake a cost analysis of alternative technologies that allow for $\mathrm{CO}_{2}$ capture.

Estimates for alternative technical approaches to the SOFC/OTM approach are taken from the work of Simbeck ${ }^{1,2}$. In these studies, Simbeck calculates the costs of $\mathrm{CO}_{2}$ separation, capture, drying and compression to 135 bar. He reports costs in terms of an incremental capital charge, in $\$ / \mathrm{kWe}$ generated, as well as reporting the cost in $\$ / m$ ton $\mathrm{CO}_{2}$ captured in each process. Net system efficiencies, accounting for the losses of separation and compression are also reported.

\begin{tabular}{|c|c|c|c|c|c|}
\hline Alternative & $\begin{array}{c}\text { System } \\
\text { Electrical } \\
\text { Efficiency, } \\
\%\end{array}$ & $\begin{array}{c}\text { Elec } \\
\text { Cost, } \\
\$ / \mathbf{k W h}\end{array}$ & $\begin{array}{c}\text { Incr. Cost/ } \\
\text { Metric Ton } \\
\text { CO2 } \\
\text { Rel. to NGCC } \\
\text { Baseline, } \\
\$ / \text { Mton CO2 } \\
\end{array}$ & $\begin{array}{l}\text { Ratio Alt. ton } \\
\text { CO2 / } \\
\text { SOFC ton } \\
\text { CO2 }\end{array}$ & $\begin{array}{l}\text { Competitive } \\
\text { Price for } \\
\text { SOFC, } \\
\text { \$/Metric Ton } \\
\text { CO2 }\end{array}$ \\
\hline \multicolumn{6}{|l|}{ Gas Based Alternatives $^{1}$} \\
\hline NGCC + Flue Gas CO2 Scrubber & 52 & 0.049 & 60 & 0.87 & 52.2 \\
\hline Autothermal Reformer + H2 Fired CC & 48 & 0.051 & 69 & 0.94 & 64.86 \\
\hline Methanol Type Reformer + H2 Fired CC & 51 & 0.049 & 60 & 0.88 & 52.8 \\
\hline NH3 Type Reformer + H2/N2 Fired CC & 51 & 0.051 & 67 & 0.88 & 58.96 \\
\hline Adv. O2 Fired NGCC & 48 & 0.051 & 60 & 0.94 & 56.4 \\
\hline Adv. H2/O2 Cycle & 52 & 0.053 & 65 & 0.87 & 56.55 \\
\hline \multicolumn{6}{|l|}{ Coal Based Alternatives $^{1}$} \\
\hline Adv O2 Fired PC Boiler & 33 & 0.064 & 99 & 1.37 & 135.63 \\
\hline Adv O2 Fired PFBC & 34 & 0.063 & 105 & 1.32 & 138.6 \\
\hline Adv Hot CO2 Recovery + PFBC & 39 & 0.053 & 85 & 1.15 & 97.75 \\
\hline H2 CGCC+ Syngas Scrubber & 39 & 0.051 & 81 & 1.25 & 101.25 \\
\hline Adv H2/O2 Rankine Cycle & 38 & 0.059 & 84 & 1.18 & 99.12 \\
\hline Adv Cas CU + H2 CGCC & 40 & 0.047 & 73 & 1.13 & 82.49 \\
\hline \multicolumn{6}{|l|}{ Tax Based Alternatives } \\
\hline Current CO2 Credit Transactions & & & 20 & & 20 \\
\hline Norwegian CO2 Emissions Tax & & & 41 & & 41 \\
\hline Proposed European Tax ${ }^{2}$ & & & 100 & & 100 \\
\hline
\end{tabular}


Figure 2 lists the most competitive alternatives selected from Simbeck's report. The most competitive gas-fired alternatives show costs for capture and compression of $\$ 60-70 /$ metric ton of $\mathrm{CO}_{2}$ captured. Correcting for the amount of $\mathrm{CO}_{2}$ generated per kWe for these alternatives relative to SOFC/OTM option suggests the incremental value of $\mathrm{CO}_{2}$ capture \& compression for the SOFC/OTM concept is $\$ 52-65 /$ mton. In similar manner, coal-fired generating alternatives suggest competitive values for SOFC as high as $\$ 82-100 /$ mton.

Figure 2 also lists three tax-based assessments. In recent trades, $\mathrm{CO}_{2}$ credits have traded at $\$ 6$ $20 /$ mton. The current Norwegian tax for $\mathrm{CO}_{2}$ emissions is US\$41/mton. If the cost $/$ mton of alternative solutions continue to exceed current trading prices or emissions taxes, those trading prices or taxes will increase to a point of equilibrium. The table also includes a proposed European tax ${ }^{3}$ of $\$ 100 / \mathrm{mton}^{2}$ with proposed effective date of 2008. A mix of both gas-fired and coal-fired generating plants will be required to serve future US and global generation needs. Therefore a mean cost of US $\$ 60 / \mathrm{mton}^{\mathrm{CO}} \mathrm{O}_{2}$ is deemed the competitive incremental cost to add $\mathrm{CO}_{2}$ capture capability to the SOFC generator. Using $\$ 60 /$ mton $\mathrm{CO}_{2}$, project life of 10 years, $98 \%$ availability and $15 \%$ capital recovery factor, the equivalent competitive cost premium for $\mathrm{CO}_{2}$ capture in SOFC generators is $\$ 1500 / \mathrm{kWe}$. This number includes the additional capital cost for compressors as well as any difference in present value of compressor energy for the competing systems.

Simbeck's costs for $\mathrm{CO}_{2}$ capture, drying and compression were based on systems with a range of separation pressures. The SOFC/OTM capture technology described here can be deployed on either atmospheric or pressurized SOFC systems. For the atmospheric SOFC option, an additional compressor stage is required. Simbeck estimates $\$ 26 / \mathrm{kWe}$ for a three-stage compressor train to increase pressure from 3 to 135 bar.

Simbeck's estimates of the energy required for compression is lower than SWPC estimates. Siemens Westinghouse estimates the energy to increase $\mathrm{CO}_{2}$ pressure from 1 to 135 bar is more conservatively stated as $9 \%$ of the system output. Assuming a value of electricity of $\$ 0.05 / \mathrm{kWh}$, this energy loss equates to a present value of $\$ 250 / \mathrm{kWe}$.

The net competitive value for the $\mathrm{CO}_{2}$ capture and sequestration option for the SOFC/OTM zero emission power generation system is therefore $\$ 1,250 / \mathrm{kWe}$.

\section{2: Target Setting}

Based on this analysis, the maximum allowable additional capital cost for a zero emission SOFC/OTM system is $\$ 1,250 / \mathrm{kWe}$. This cost has to cover all of the costs related to separate the anode and cathode gas streams of the SOFC as well as the cost of the OTM afterburner module. In lack of a more precise method to derive individual targets, $20 \%$ of the total is assigned to the additional cost for the SOFC and $80 \%$ is allocated to the OTM. The target becomes $\$ 250 / \mathrm{kWe}$ for the additional costs associated with separating the anode and cathode streams of the SOFC and $\$ 1,000 / \mathrm{kWe}$ for manufacturing and procurement of the OTM module and balance of plant.

The SOFC and OTM modules are similar in nature in that they are both tubular high temperature ceramic systems. The similarity of the two systems allows for a high level of integration of the balance-of-plant components for the SOFC and OTM afterburner. In this study $75 \%$ of the target of $\$ 1,000 / \mathrm{kWe}$ was assumed to be available for OTM tubes \& module and $25 \%$ is available for BOP components. OTM target flux values were calculated by assuming that $\$ 750 / \mathrm{kWe}$ of the SOFC was available for manufacture of the OTM tubes and afterburner module. 


\section{TASK 2 - MATERIALS DEVELOPMENT}

Praxair has developed a portfolio of OTM material compositions applicable for use in various applications. The materials portfolio is broadly classified into those suitable for 'reactive' and 'nonreactive' applications. An example of a 'non-reactive' application is stand-alone oxygen production. In this case air is pressured on one side of the OTM and oxygen is collected at ambient pressure at the other. An example of a 'reactive' application is in synthesis gas (syngas) production. In syngas production, low-pressure air is directed to one side of the membrane and a mixture of de-sulphurized natural gas and steam is directed to the other side of the membrane at a significantly higher pressure. Both of the aforementioned OTM applications involve high temperatures and significant pressure differentials. The SOFC/OTM zero emission power generation application described here is less demanding in that both air and fuel are fed to the OTMs at low pressure. This means that there is less demanded of the OTM in terms of strength and mechanical robustness. The SOFC/OTM power generation application is more similar in nature to the syngas application in that the selected material is required to be stable over a wide range of oxygen partial pressure. Therefore, material screening was performed on compositions selected from Praxair's portfolio of 'reactive' OTM materials. The criteria used to screen the materials are listed below:

- Oxygen ion and electronic conductivity

- Chemical stability in a range of oxygen activities from 1 to $10^{-15}$ atm.

- Thermal and compositional expansion - Many established OTM materials lose oxygen and expand when equilibrated in fuel (low $\mathrm{pO}_{2}$ ), after manufacture in air.

- Phase stability and low volatility at operating and sintering temperatures

- Ease of fabrication

- Moderate to high tensile strength and low creep rate

- Moderate cost of raw materials and fabrication.

Early in the project, three OTM material compositions were screened for flux, strength and chemical expansion. In order to make progress with the design and manufacture of demonstration-sized membranes a decision on the material composition was made early in the project. For clarity the properties of the selected material composition (PXAB2) are discussed within Task 4 (Measurement of oxygen flux in tubular OTM reactors). 


\section{TASK 3 - DESIGN AND FABRICATION OF TUBULAR OTMS}

Starting powders used to manufacture the OTM tubes were manufactured by a patented combustion spray pyrolysis technique developed by Praxair Specialty Ceramics (PSC). Constituent metals in the form of a salt solution are mixed with a fuel that is combusted in a spray drier. The result is a readily sinterable, sub-micron sized, homogeneous ceramic oxide powder.

Green tubes are manufactured by compacted the powders using an patented isostatic-pressing technique ${ }^{4}$. A watertight, cylindrical polymeric mold centered on a metallic mandrel is filled with the ceramic powder. The molds are placed in a liquid chamber and pressurized to shape the tube. The mold is removed from the liquid and the compacted powder, shaped as a closed-one-end tube is sintered to form the dense ceramic.

Laboratory-scale membranes had $14 \mathrm{~cm}\left(5.5 \mathrm{in}\right.$.) active length and $77 \mathrm{~cm}^{2}\left(12 \mathrm{in.}^{2}\right)$ exposed surface area. Demonstration-sized membranes (Figure 3) had $135 \mathrm{~cm}\left(53 \mathrm{in}\right.$.) active length and $750 \mathrm{~cm}^{2}(116$ in. ${ }^{2}$ ) exposed surface area. The isostatic press, located at Praxair Surface Technologies (PST) in Indianapolis can accommodate green tubes up to 140 inches in length.

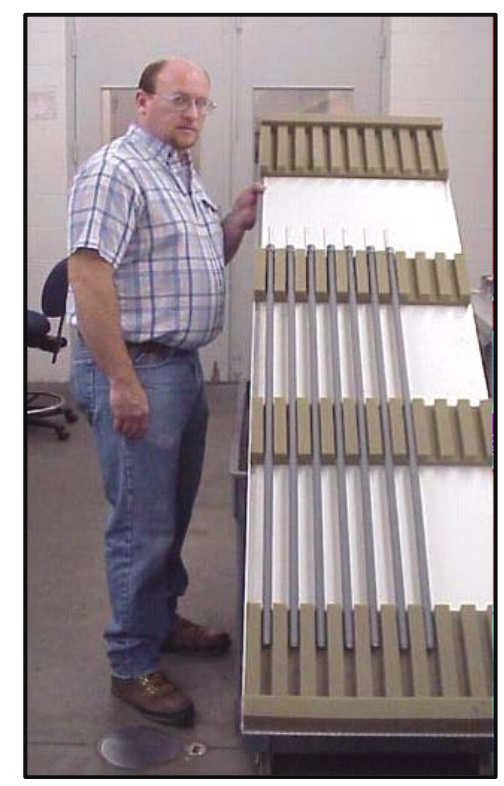

Figure 3: Photograph of as manufactured, demonstration-sized tubular membranes 


\section{TASK 4 - MEASUREMENT OF OXYGEN FLUX IN TUBULAR OTMS}

\section{1: Introduction}

In total over 16,700 hours of membrane testing were completed in this program - about 10,700 hours of laboratory-scale membrane testing at Praxair and 6000 hours of demonstration-sized membrane testing at SWPC. Seven tests operated continually for over a month (730 hours), four tests for over two months (1460 hours), three over three months (2190 hours) and one which continually operated for almost 3500 hours or nearly five months. This section provides an overview of experimental methods and details the key-learnings from OTM performance tests in both relatively inert, as well as contaminated operating environments.

\section{2: Experimental Approach}

Laboratory-scale OTM performance evaluations were conducted in two reactors constructed at Praxair. To accommodate the larger, demonstration-sized membranes, an existing single-cell SOFC test stand at SWPC was modified. Photographs of the reactors are shown in Figure 4.
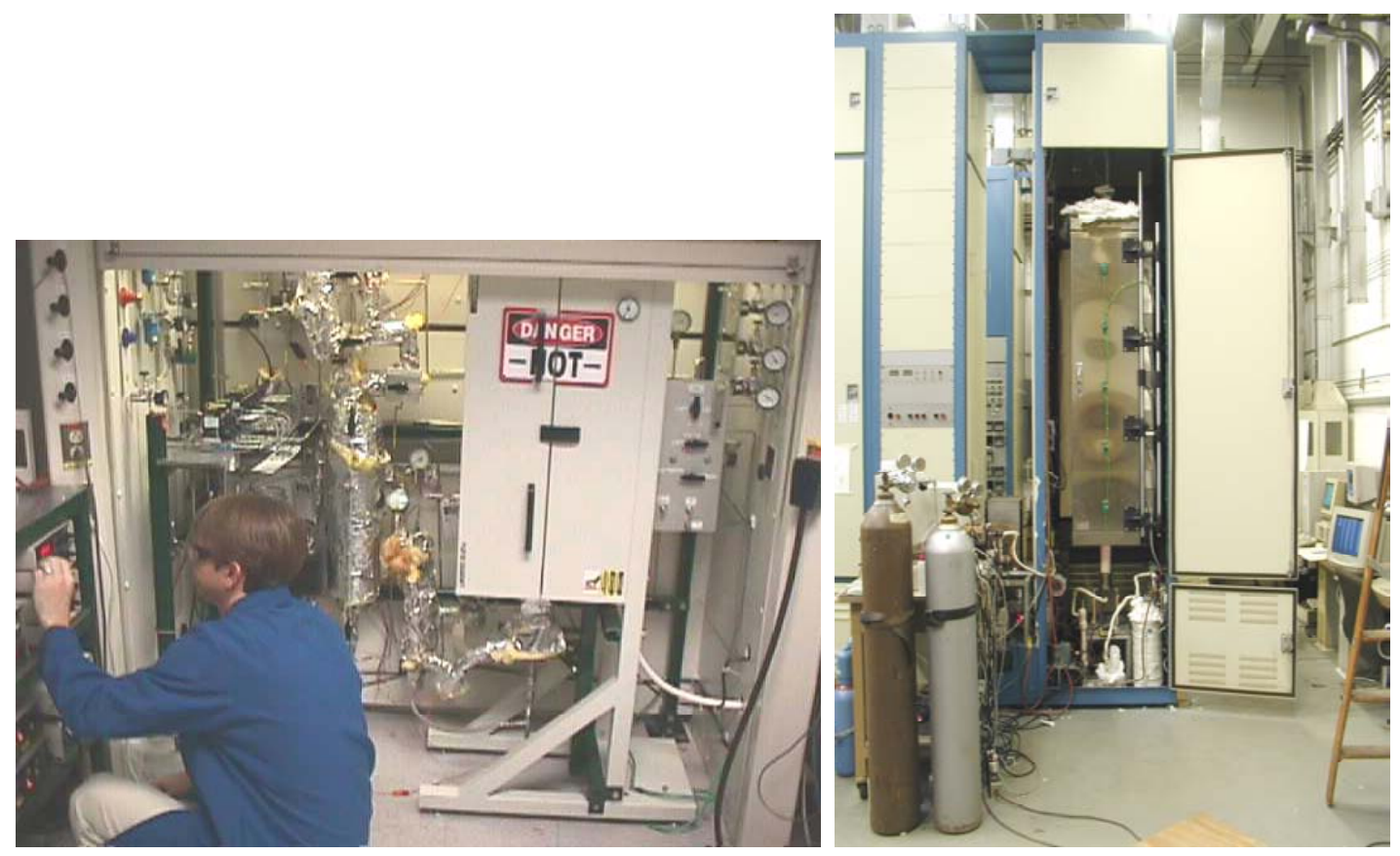

Figure 4: Photographs of the Laboratory-Scale and Demonstration-Sized, Single Tube OTM Reactors at Praxair and SWPC

A schematic of a Praxair laboratory-scale reactor is shown in Figure 5. At Praxair, the OTMs were tested within a cylindrical $\mathrm{Al}_{2} \mathrm{O}_{3}$ reactor shell, heated within a furnace to approximately $1000^{\circ} \mathrm{C}$. The membrane was sealed using a proprietary high-temperature mechanical seal. Air was delivered to the inside of the OTM via an $\mathrm{Al}_{2} \mathrm{O}_{3}$ feed tube, which ended $1.5 \mathrm{~cm}(0.6$ ") from the membrane's closed end. Upon emerging from the feed tube, air flowed from the closed end toward the open end of the membrane in the annular space between the ID of the membrane and the OD of the feed tube. Air feed pressure was typically 1.75 psig. 
Simulated SOFC exhaust gas flowed over the membrane's external surface from the closed end toward the open end of the membrane, co-currently with the air stream, within the annular space between the OD of the membrane and the ID of the reactor shell. The fuel gas inlet composition was controlled at $63.0 \% \mathrm{H}_{2} \mathrm{O}, 21.7 \% \mathrm{CO}_{2}, 3.7 \% \mathrm{CO}$ and $11.6 \% \mathrm{H}_{2}$, which reflected the exhaust from an SOFC stack operating at $85 \%$ fuel utilization, with a steam-based buffer seal (Section 5.1). Typically, total fuel flow rates (at $1 \mathrm{psig}$ ) were varied to achieve complete oxidation of the fuel stream with minimal excess permeated $\mathrm{O}_{2}$.

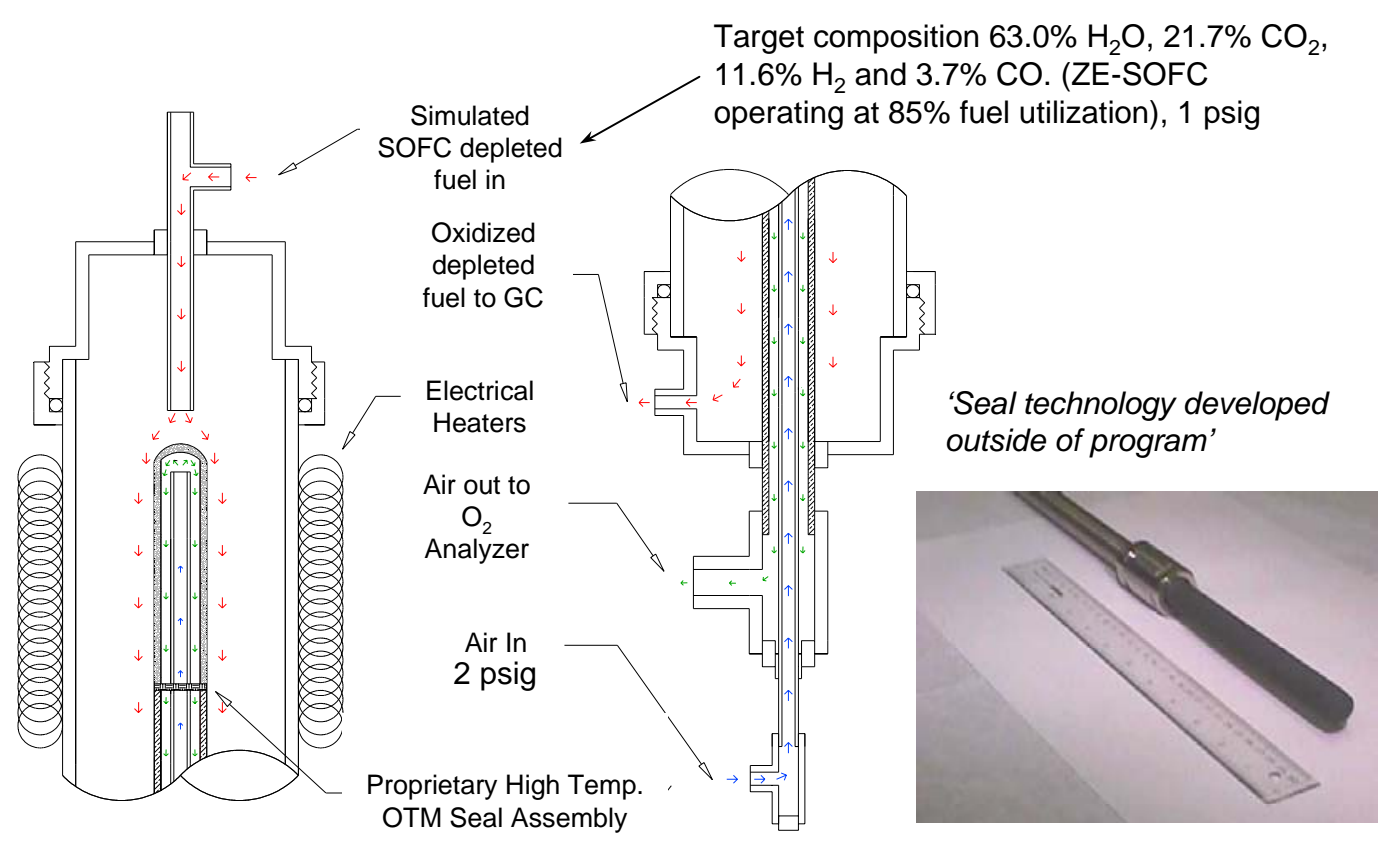

Figure 5: Schematic of the Praxair Laboratory-Scale, Single Tube OTM Reactor

Oxygen flux through the OTM could be independently calculated and checked for consistency using both air-side monitoring (e.g. air mass flow controllers, meters, and oxygen analyzer) and fuel side monitoring (e.g. fuel mass flow controllers, meters, and GC). By monitoring the amount of $\mathrm{N}_{2}$ leaking from the air to the fuel side of the OTM during operation, the oxygen flux could also be adjusted to exclude any leak effects. Using this methodology, leak-corrected average $\mathrm{O}_{2}$ fluxes for the OTM were measured and reported.

Figure 6 shows a schematic of the reactor at SWPC used to evaluate demonstration-scale membranes. There are several differences as compared to the Praxair OTM reactors, as in the SWPC set-up, the reactor module was constructed in an existing SOFC test stand at SWPC. Most noticeably, the demonstration-sized OTMs were evaluated without a Praxair seal, and in an inverted position relative to the Praxair tests. Despite these differences, however, it was demonstrated that comparable data could be obtained from both test stands. 


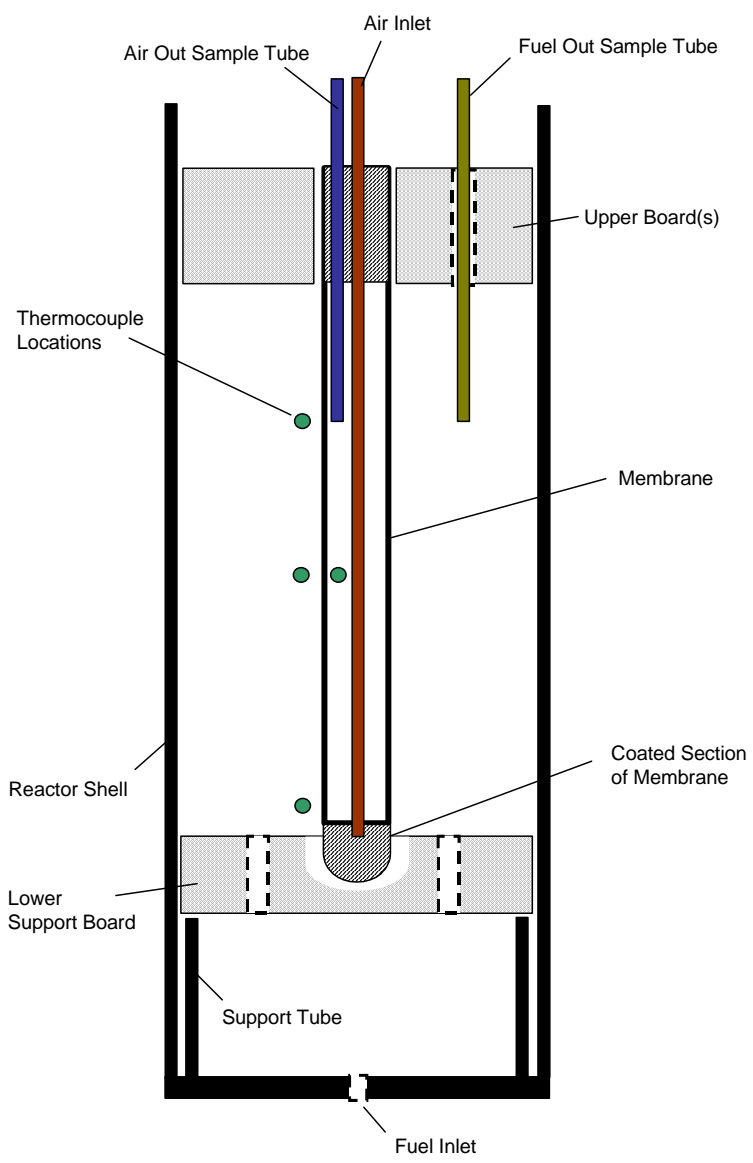

Figure 6: Schematic of the SWPC Demonstration-Sized, Single-Tube, OTM Reactor

The demonstration-sized membrane at SWPC was situated within an $\mathrm{Al}_{2} \mathrm{O}_{3}$ reactor shell, oriented with the closed end downward. The OTM was supported on a ceramic fiberboard, cushioned using with ceramic wool. This lower board was in turn supported on an $\mathrm{Al}_{2} \mathrm{O}_{3}$ support tube, used to axially center the membrane within the shell and furnace. Thick ceramic fiberboard was used at the open end of the membrane to radially center the membrane and 'seal' it into place. Practically, the boards did not provide a true seal, but rather were used to provide a sufficient flow restriction so that a portion of the effluent fuel stream would be diverted through fuel sample tube. This sample tube was inserted through the boards, and extended past the bottom edge of the upper boards, effectively reducing the measured active length of the membrane to roughly $110 \mathrm{~cm}$ (43 in.). 
Air was introduced inside of the membrane via an $\mathrm{Al}_{2} \mathrm{O}_{3}$ feed tube, which ended about $2.5 \mathrm{~cm}$ ( 1 in.) from the closed end of the tube. Air would then flow up the reactor, co-concurrent with the fuel, in the annular space between the feed tube and the membrane. The open end of the membrane was packed with inorganic wool in order to divert as much flow as possible through the $\mathrm{Al}_{2} \mathrm{O}_{3}$ air sample tube, which was located below the bottom edge of the upper boards, level with the fuel sampling tube.

As in the Praxair reactors, simulated SOFC exhaust gas flowed over the membrane's external surface from the closed end toward the open end of the membrane, co-currently with the air stream, within the annular space between the OD of the membrane and the ID of the reactor shell. Any fuel and air not passing through the outlet sample tubes was allowed to mix and vent directly to a capture source.

Air and fuel pressures were somewhat lower than in Praxair tests, typically 1.3 and 0.1 psig, respectively. Otherwise, reactor operation and data analysis were conducted in a manner similar to that described above for the Praxair, laboratory-scale reactors.

\section{3: OTM Flux and Stability}

Throughout the project, it was repeatedly demonstrated on both laboratory-scale and demonstrationsized membranes that simulated, depleted fuel streams from the SOFC anode (e.g. $60 \% \mathrm{H}_{2} \mathrm{O}, 25 \%$ $\mathrm{CO}, 12 \% \mathrm{H}_{2}, 3 \% \mathrm{CO}$ ) could be completely oxidized using unmodified dense membranes without the need for additional membrane oxidation catalysts. Readily sequesterable afterburner exhaust streams were produced, with dried afterburner effluent compositions of $97-99.5 \% \mathrm{CO}_{2}, 0-2 \% \mathrm{O}_{2}$, and $0-1 \% \mathrm{~N}_{2}$ being common. Residual $\mathrm{CO}$ and $\mathrm{H}_{2}$ were not detected to the detection limits of the gas chromatograph (<10 ppm). Such performance was regularly achieved using dense membranes, which typically exhibited a leak-corrected, average flux of between 30 to $40 \%$ of the targeted value.

In order to meet the flux targets set in the initial system study (Task 1), improvements were required. Membrane shrouding was examined to enhance fuel-side, gas-phase mass transfer, but no appreciable benefit was obtained. However, when various proprietary modifications were introduced, flux values within the target range were achieved (see figure 7).

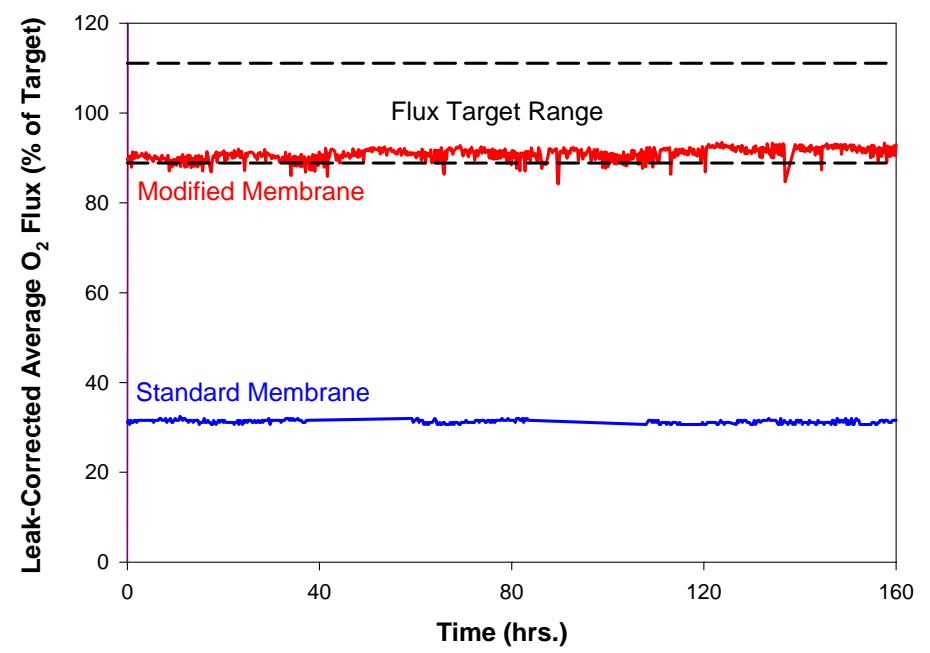

Figure 7: Comparison of standard OTM versus modified OTM flux as percentage of target 
Many early tests focused on short-term evaluation of OTM performance. However, in order to develop a successful afterburner technology, performance stability must be demonstrated. The economic life cycle of the active OTM elements in commercial OTM afterburner must be at least equal to the active ceramic elements in the SOFC (i.e. > 10 years). Concerns existed that, over an extended period, the membranes would react in the high concentrations of $\mathrm{CO}_{2}$ and $\mathrm{H}_{2} \mathrm{O}$ exiting the OTM afterburner exhaust to form carbonates and hydroxides. Thus, several long-term performance stability tests were conducted to gauge stability in the relatively inert environment of the single-tube OTM reactors. Two tests at Praxair and SWPC focused on laboratory-scale and demonstration-sized unmodified dense membranes, respectively.
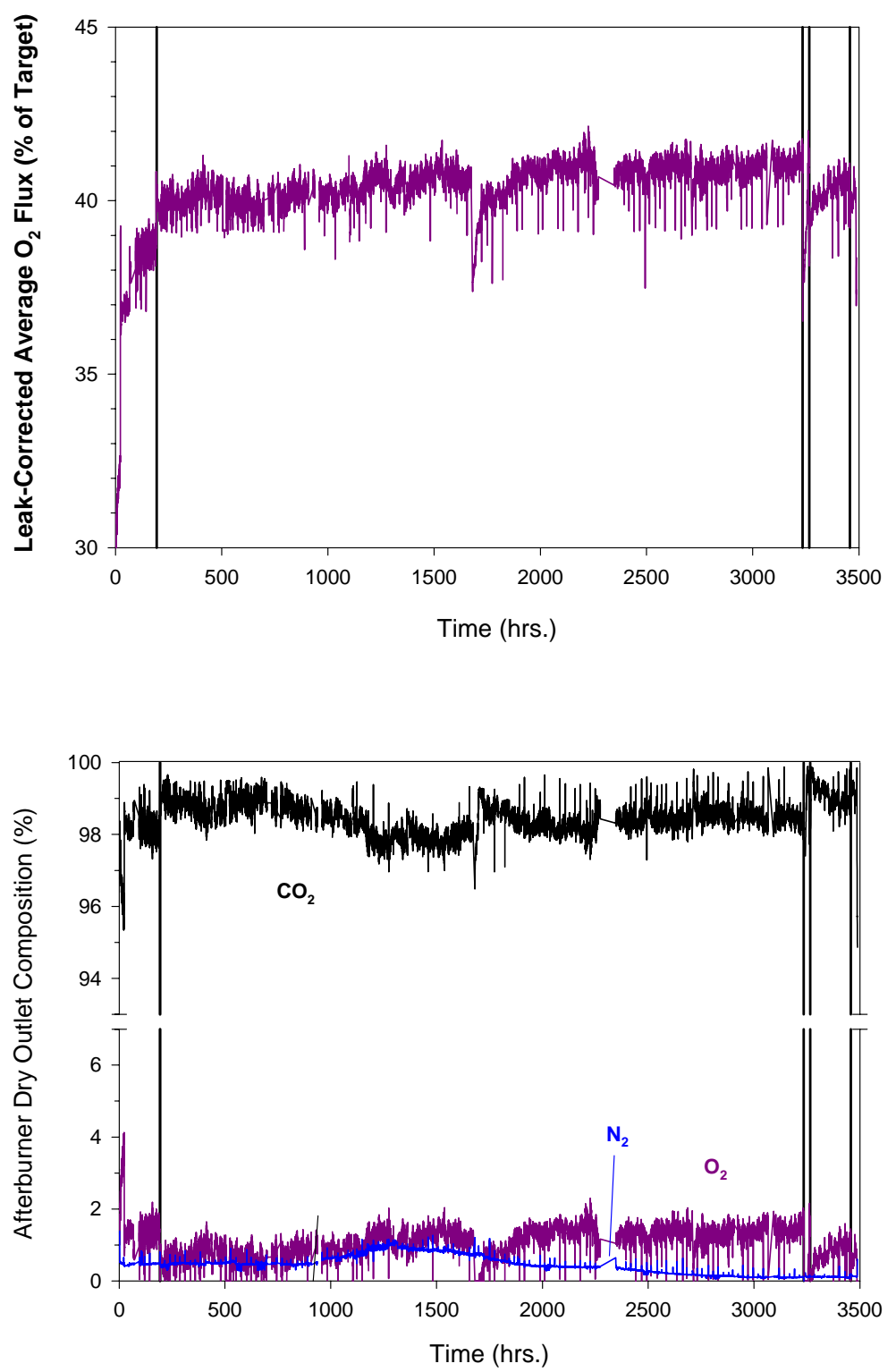

Figure 8: Leak-corrected average $\mathrm{O}_{2}$ flux (top) and dried afterburner exhaust composition (bottom) over the 3500 hrs. testing of a laboratory-sized, un-modified OTM at Praxair. 
As shown in figure 8, under complete oxidation conditions in the afterburner, the laboratory-scale membrane evaluated at Praxair exhibited a stable flux of $40 \%$ target for $>3500$ hours with a dried exhaust composition of 98 to $99 \% \mathrm{CO}_{2}, 0.5$ to $1.5 \% \mathrm{O}_{2}$, and 0 to $0.5 \% \mathrm{~N}_{2}$. The vertical line at 194 hours in figure 8 corresponds to the end of fuel flow adjustment, and arrival at steady state. Although not explicitly denoted, between 194 and 3235 hours the membrane underwent five controlled gas composition cycles in order to change out cylinders and replenish the fuel gas supply.
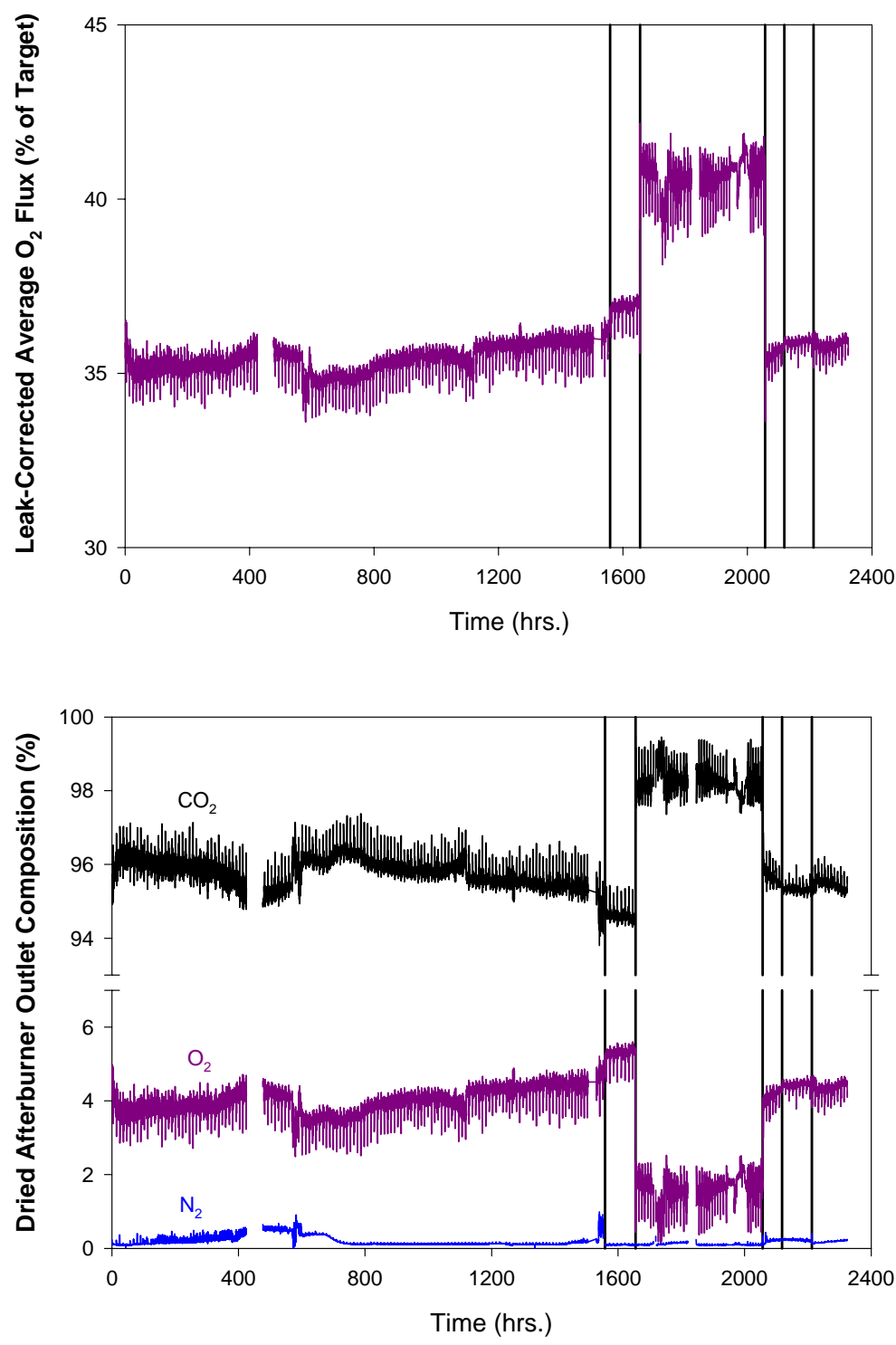

Figure 9: Leak-corrected average $\mathrm{O}_{2}$ flux (top) and dried afterburner exhaust composition (bottom) over the 2300 hrs. of testing a demonstration-sized, unmodified OTM at SWPC. 
As shown in Figure 9, the demonstration-sized membrane tested at SWPC exhibited a stable flux of $36 \%$ of target with $4 \%$ excess $\mathrm{O}_{2}$ for over $2300 \mathrm{hrs}$. When operated at $1.5 \%$ excess $\mathrm{O}_{2}$ for about 400 hrs., the flux increased to $41 \%$ of target, closely matching the laboratory-scale membrane performance at Praxair. The vertical line at 1500 hours indicates a $75 \%$ increase in airflow rate, which only had a minor impact on flux. The vertical line at 1650 hours represents the $25 \%$ increase in fuel flow rate, which reduced the excess permeated $\mathrm{O}_{2}$ in the dried effluent to about $1.5 \%$ and increased flux significantly. Upon returning to the original fuel flow rates at $2050 \mathrm{hrs}$., the OTM was subjected to four controlled gas composition and thermal cycles between room and operating temperature. The membrane flux was unaffected by these cycles. Finally, the OTM was subjected to several thermal and compositional shocks, which are described in more detail in section 4.5.

Despite concerns, no evidence of carbonate or hydroxide formation was observed in either test. Both tests indicated good OTM performance in the simulated SOFC anode exhaust over extended periods.

Long term stability was also demonstrated in another test at SWPC, which evaluated a modified, highflux, demonstration-sized membrane. Figure 10 shows the results from this test, in which the OTM exhibited stable fluxes of up to $70 \%$ target at $2 \%$ excess permeated $\mathrm{O}_{2}$ in the dried afterburner exhaust stream (not shown). In figure 10, the multiple step changes in flux up to $1000 \mathrm{hrs}$. are caused by corresponding increases in fuel flow rate. The steady-state flux recorded in this experiment was somewhat lower than that observed during the laboratory-scale tests at Praxair (i.e. $70 \%$ vs. $90 \%$ target). This is likely because the OTM used in this 2500-hour test was among the very first modified, demonstration-sized membranes to be produced. Manufacturing techniques had not yet been optimized, as they had for the laboratory-scale membranes. Future batches of modified OTMs will benefit from optimization and thus meeting target flux for this application is not seen to be a major hurdle.

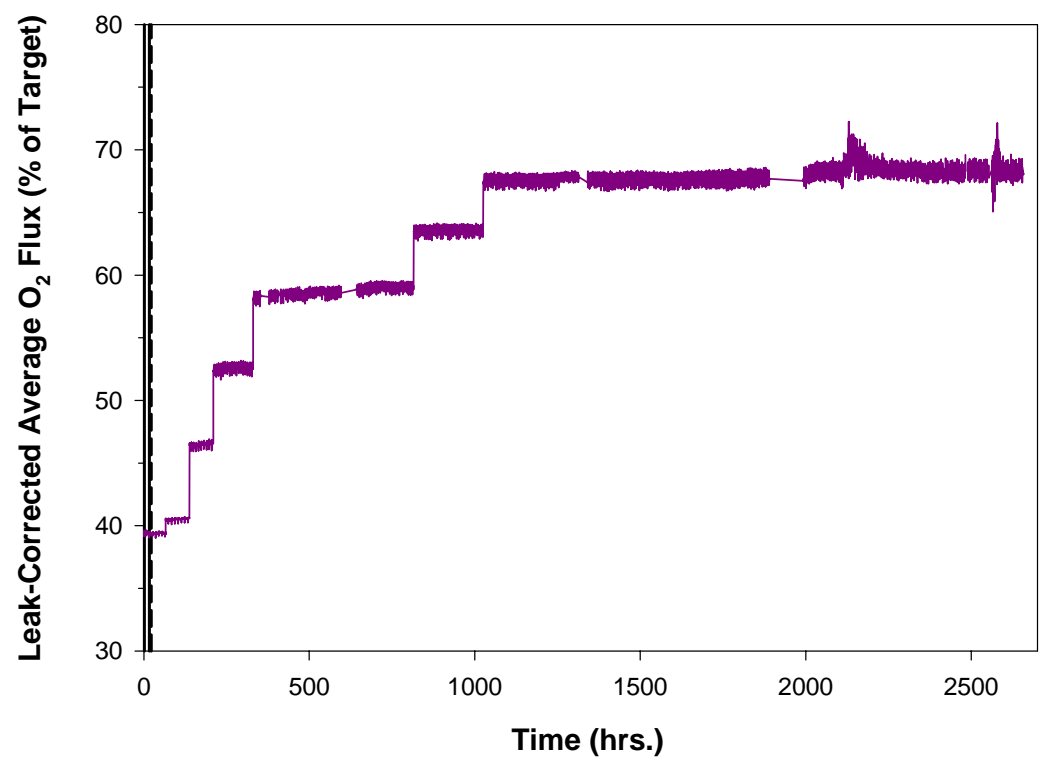

Figure 10: Leak-corrected average $\mathrm{O}_{2}$ flux over the $2500 \mathrm{hrs}$. of testing a modified, high-flux, demonstration-sized OTM at SWPC. 
The above tests proved that target fluxes and performance stability suitable to justify proceeding with a demonstration could both be achieved in the reducing environment of a simulated SOFC anode exhaust and in the relatively inert environment of an $\mathrm{Al}_{2} \mathrm{O}_{3}$ reactor.

\section{4: OTM Stability towards chemical contamination}

It is well known that in high temperature systems, Cr-species can be volatilized from hot surfaces of the high temperature alloys used to construct the reactors. This problem has been particularly critical in SOFC design. Experience has shown that the volatized $\mathrm{Cr}$-species have a tendency to recondense at the cathode/electrolyte interface, rapidly degrading the performance of the SOFC ${ }^{5,6,7}$.

High-temperature system engineering experience gained from SOFC development has established that gas-phase Si-species are formed when steam-containing process streams wet the surface of high temperature insulation materials. In a similar manner to the Cr-problem, it has also been proven that should these gas-phase Si-species be allowed to re-condense at electrochemically active sites in the SOFC, the resulting performance degradation can be catastrophic ${ }^{8}$

The OTM operates in a very similar manner to a SOFC, in both cases oxygen is transported as $\mathrm{O}^{2-}$ ions through vacancies in the dense walled ceramic membranes. It was anticipated that gas-phase Cr-species, volatilized from high-temperature surfaces of metal alloys used to construct the OTM module. Also gas-phase Si-species would form when steam-containing process streams contacted silica containing insulation material. Both elements would likely re-condense on the OTMs and catastrophically degrade performance.

\subsection{1: High temperature metals}

In flat-plate SOFC stacks containing high-temperature, metal-alloy interconnect (or bi-polar) plates, the problem of $\mathrm{Cr}$-evaporation has been addressed by coating the metal plates with various perovskite materials. A popular solution has been to use vacuum plasma spray techniques to coat the surface of the plates with $\mathrm{LaCrO}_{3}$ based perovskites. The principal consideration in developing these solutions has been that the interconnect alloys in the flat plate SOFC stacks need to provide a low-resistance electrical contact between the anodes and cathodes of adjacent cells. This precludes any passivation technique involving the formation of insulating oxide layers on the surface of the metal alloys. Although workable solutions to the Cr-contamination problem have been demonstrated, the aforementioned flat-plat SOFC solutions involving the fabrication of relatively dense, perovskite surface coatings of the high temperature metallic components adds considerable cost to stack manufacture.

In the tubular OTM case the problem is much simpler since metal alloys are used only in structural (not electrical) components. Praxair focussed on evaluating high temperature metal-alloys that formed $\mathrm{Al}_{2} \mathrm{O}_{3}$ surface oxide layers after annealing at high-temperature. Praxair surveyed the availability, strength, mechanical strength and workability of the known $\mathrm{Al}_{2} \mathrm{O}_{3}$-scale forming high temperature alloys. One alloy, designated reactor alloy $A$, was selected for further investigation. The alloy was selected primarily on the basis of availability, with short-lead time, in tube, sheet and bar stock form pending a near-term demonstration of the technology.

In one laboratory-sized membrane test at Praxair, a pre-oxidized 'reactor alloy A' tube was used as the tube used to feed air at high temperature $\left(\sim 1000^{\circ} \mathrm{C}\right)$ to the inside of the laboratory-scale OTM. In all previous tests the air feed tubes had been manufactured from $\mathrm{Al}_{2} \mathrm{O}_{3}$. 
Figure 11 shows leak-corrected oxygen flux data, as a percentage of target for the $\sim 700$ hour test. Although some deterioration in the oxygen flux through the membrane was observed, the degradation was in no way catastrophic.

Figure 12 is a scanning electron micrograph showing a cross-section through the 'reactor alloy A' airfeed tube following the $\sim 700$ hour test. The outer surface oxide layer that formed on the air-feed tube is primarily $\mathrm{Al}_{2} \mathrm{O}_{3}, \mathrm{Cr}_{2} \mathrm{O}_{3}$ containing oxide layers were formed beneath the $\mathrm{Al}_{2} \mathrm{O}_{3}$ surface layer.

Reactor alloy A was selected primarily on the basis of availability for use within a near-term demonstration of the SOFC/OTM technology. On the basis of the presented data it is proposed that the selected alloy would be suitable for use in a short-term technology demonstration but not in commercial application of the technology for which, 10 year life of the SOFC \& OTM active ceramic elements is targeted.

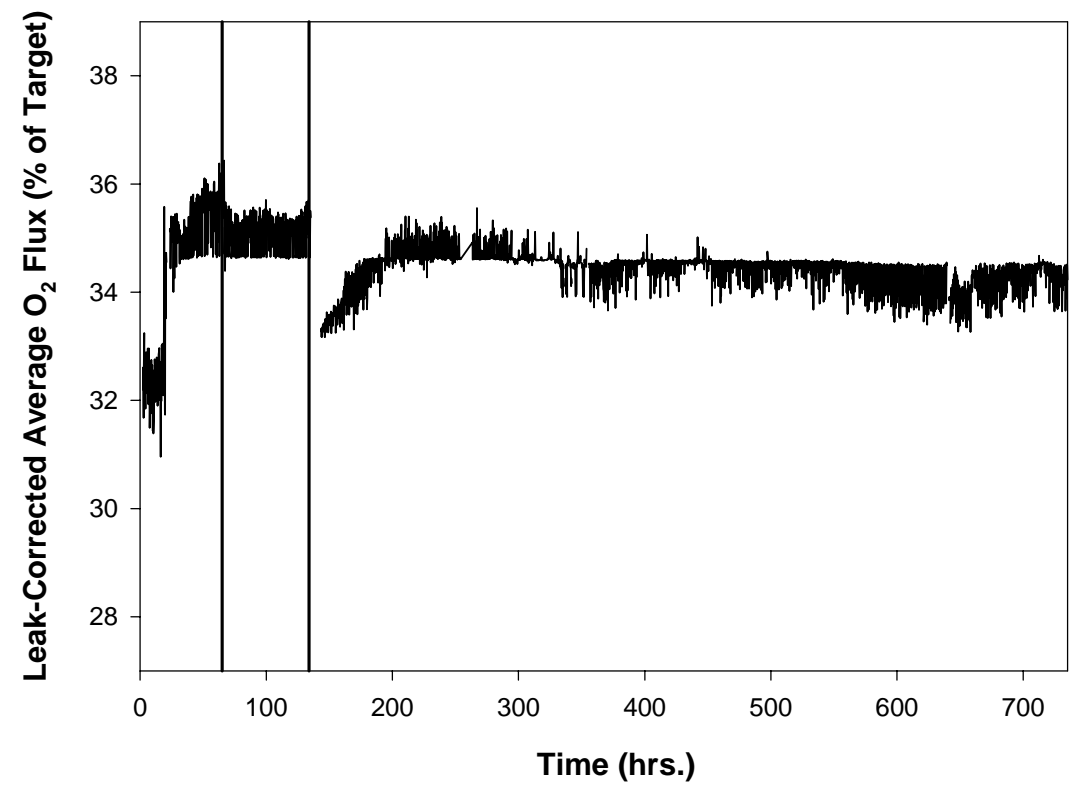

Figure 11: Leak-corrected average oxygen flux as a function of time when using a 'reactor alloy $A$ ' airfeed tube in a laboratory-scale, OTM test at Praxair. 


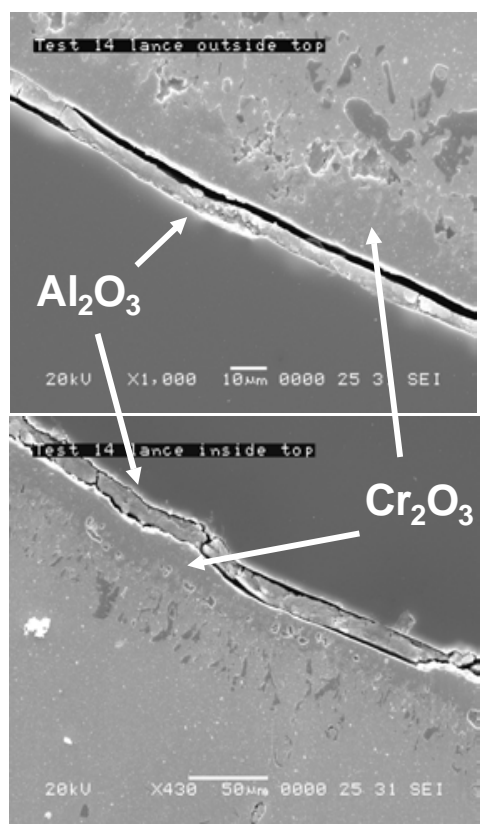

Figure 12: Scanning electron micrograph showing a cross-section of the 'reactor alloy $A$ ' air-feed tube following the 700 hour OTM test.

\subsection{2: High temperature insulation}

Silicon-based membrane contamination from insulation containing silica and means to prevent such contamination were studied in detail during the final months of the project. Praxair modified one of the laboratory-scale OTM reactors so that simulated SOFC exhaust gas could be passed through a bed of silica-containing insulation material at high temperature before the stream was allowed to impinge upon the outer surface of the OTM (see Figure 13). 


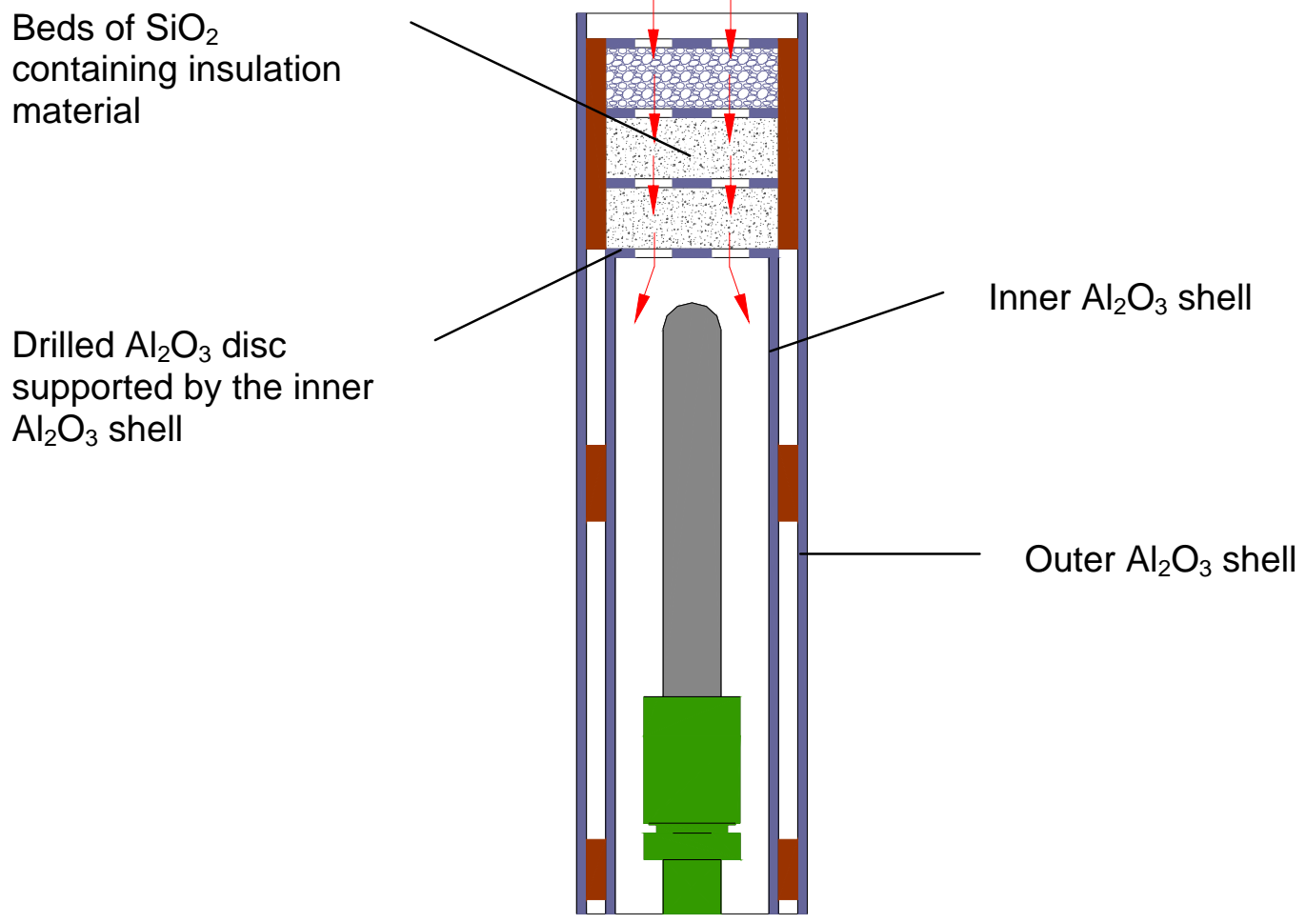

Figure 13: Schematic of the modified laboratory-scale OTM reactor at Praxair to facilitate $\mathrm{SiO}_{2}{ }_{-}$-based OTM contamination testing.

A control experiment was carried out in order to determine baseline degradation rates associated with introducing $\mathrm{SiO}_{2}$-based contaminants into the fuel gas process stream. Results of the control experiment are included in Figure 14. It can be seen from Figure 14 that $\mathrm{SiO}_{2}$, transported in the fuel stream in the form of a volatilized, vapor-phase species rapidly and catastrophically degrades the OTM membrane performance. The OTM performance degradation rate measured in this experiment was $\sim 0.2 \% /$ hour.

Standard un-modified, laboratory-scale OTMs were used in these tests. The magnitude of the oxygen flux measured in this series of experiments was significantly higher than that recorded in previous tests for similar membranes. The data shown in Figure 14 shows percentage of target flux values of $52-56 \%$, whereas for similar OTMs in previous tests, percentage of target flux values of 30 to $40 \%$ had been more common. One explanation for this difference is that in modifying the reactor to accommodate the $\mathrm{SiO}_{2}$ source, the heat and/or mass-transfer characteristics within the reactor may also have been significantly altered.

After the initial control experiment various means to prevent rapid OTM performance degradation caused by $\mathrm{SiO}_{2}$-based contaminants in the fuel gas process streams were devised and tested in the reactor. 


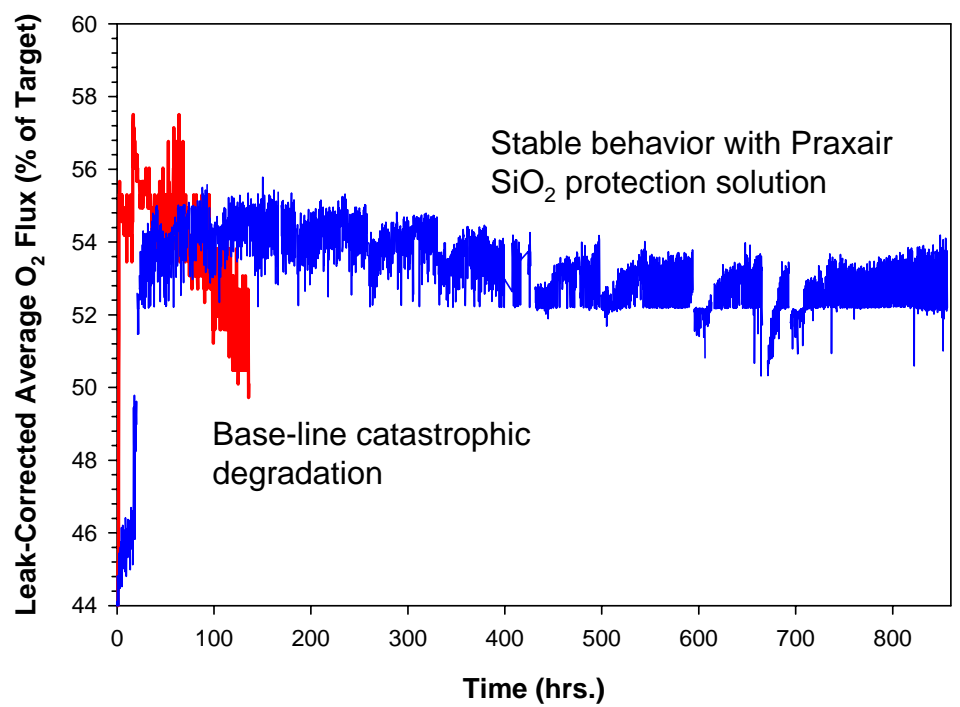

Figure 14: Plots of base-case $\mathrm{SiO}_{2}$ degradation vs. oxygen flux stability when a means to prevent the OTM degradation due to transported $\mathrm{SiO}_{2}$ was included in a laboratory-scale, OTM test at Praxair.

Praxair was successful in finding ways to prevent catastrophic degradation of the OTMs due to $\mathrm{SiO}_{2}$ based contamination. Figure 14 also shows oxygen flux stability data for an 850-hour test in which the fuel stream had been exposed to the $\mathrm{SiO}_{2}$-source in the same manner as used in the control experiment. In this experiment Praxair's proposed method of preventing transported, vapor-phase $\mathrm{SiO}_{2}$ based species from catastrophically degrading OTM performance had also built into the experiment. It is clear from the figure that catastrophic performance degradation was prevented, the control experiment OTM performance degradation rate was reduced from $0.2 \%$ /hour to no measurable degradation during the final 500 hours of testing.

Figure 15 shows the dried afterburner exhaust composition from this same test. Throughout most of the test, the dried afterburner exhaust consisted of roughly $99 \% \mathrm{CO}_{2}$, with less than $1 \% \mathrm{O}_{2}$ and less than $0.2 \% \mathrm{~N}_{2}$. Stable fuel oxidation was demonstrated and on drying, the exhaust stream was almost pure $\mathrm{CO}_{2}$, an indication of good seal performance. 


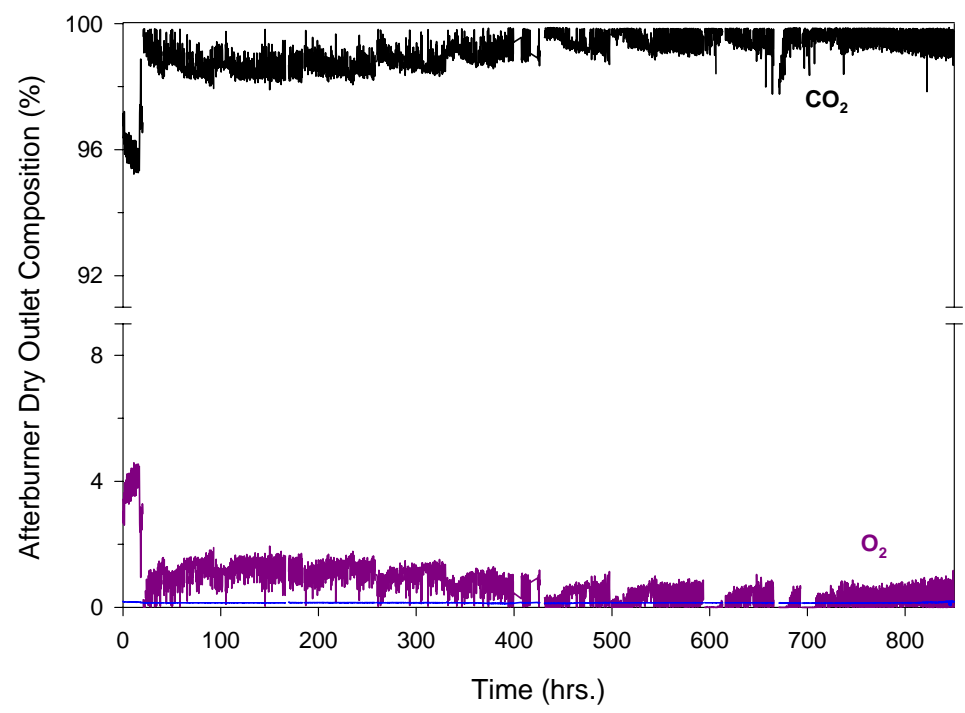

Figure 15: Dried afterburner effluent composition over the $850 \mathrm{hrs}$. of testing of a laboratory-sized, OTM at Praxair. The experiment includes a $\mathrm{SiO}_{2}$ source and a means to prevent OTM degradation.

\section{5: OTM Thermo-mechanical stability}

In addition to chemical stability, OTMs in commercial application must also be robust and mechanically resistant to various thermal and chemical shocks and cycles. A chemical shock being a rapid change in the chemical composition and therefore oxygen partial pressure of the process streams entering the OTM module. Throughout the project, both laboratory-sized and demonstrationsized membranes were subjected to such shocks. However, the bulk of the OTM thermo-mechanical stability testing was carried out by SWPC on demonstration-sized membranes.

To simulate a no-load situation in the SOFC, the typical fuel slate was quickly replaced by a stream with more concentrated fuels. Rapid heating and cooling and rapid introduction or removal of air and fuel streams to the OTM was also evaluated in order to simulate quick startups and shutdowns.

Although the OTM membranes repeatedly survived many of the thermal cycles and chemical shocks, the selected membrane material did not survive all of the imposed conditions. Improving OTM robustness and mechanical stability is a high priority in OTM research and development and more recently Praxair has developed a more robust class of OTM materials. These materials were developed and are being evaluated within ongoing OTM development programs at Praxair and Praxair's partners. 


\section{TASK 5 - SEAL DEVELOPMENT}

\section{1: OTM Seal development}

Another issue captured throughout membrane testing was seal performance. Seals, largely developed outside of this project, were applied in each laboratory-scale membrane test at Praxair. Due to the nature of the modified test stand at SWPC, the seals were not used for demonstrationsized membrane tests.

Seal performance was evaluated by considering the amount of $\mathrm{N}_{2}$ present in the dried afterburner effluent. For several tests, $\mathrm{N}_{2}$ contents as low as 0.03 to $0.1 \%$ were obtained. When extrapolated to an afterburner based on demonstration-sized membranes, the $\mathrm{N}_{2}$ concentration would drop to 30 to $100 \mathrm{ppm}$, enabling the creation of a quite pure, and readily sequesterable, $\mathrm{CO}_{2}$ stream upon drying.

On the whole, seals have been relatively robust, with stable performance over time and through various chemical and thermal cycles. However, several tests were hampered by poor seals and/or seal degradation. The proprietary Praxair seals used in laboratory-scale tests were developed for OTM applications with an external pressure on the tubes. One factor impacting seal performance in this particular application, was that the membrane was subjected to a net internal pressurization, or lift, which worked against the seal. A further limitation of the seal used in the lab-scale membrane tests at Praxair was that the seal contained threaded parts. As these threaded parts had to be tightened in order to install the OTMs, close-packing of the membranes was problematical. In the early conceptual designs of the OTM afterburner module, tubes had a relatively wide pitch.

For the reasons stated above, Praxair developed a seal concept specifically for the lower-pressure OTM afterburner application. The new seal contained no threaded parts meaning that conceptual designs of the OTM module could be developed with closer tube pitch.

\section{2: SOFC Seal development}

The SOFC seal development within this Vision 21 program was directed at the development of a sealing component for the open end of the SWPC closed-one-end tubular SOFC. A significant feature of the standard SWPC SOFC module design is a 'seal-less' flow concept that mixes the depleted anode fuel gas and the depleted cathode process air before the combined stream exits the generator module. For the Vision $21 \mathrm{CO}_{2}$ capture, the development of a sealing component which would maintain the separation of the anode and cathode gas streams and provide access to the anode gas stream for the $\mathrm{CO}_{2}$ capture was included in the program.

The availability and suitability of various SOFC seal methodologies was surveyed and it was concluded that there was nothing readily available for application to the SWPC SOFC tubular technology operating at $1000^{\circ} \mathrm{C}$. However, the concept of inserting a buffer plenum of steam between the depleted anode stream and the depleted cathode stream was judged to be a viable approach to maintaining the separation of those streams. Thus a "Steam Barrier" was chosen as the seal for continued development.

With the steam barrier placed between the anode and cathode gas plenums, it must interface with the open ends of the tubular cells. The barrier is therefore confined between plenum walls that are subjected to high temperatures and both oxidizing and reducing gases. The walls must be compatible with the SOFC materials. The steam barrier will be maintained at a slight overpressure to both the anode gas exhaust stream and the cathode gas exhaust stream, thereby mitigating any mixing of 
those streams. The combination of these requirements resulted in a number of semi-dense ceramic materials being chosen as candidates for the barrier walls.

Diffusion and permeability testing was undertaken in order to characterize the materials for transfer of $\mathrm{H}_{2}$, steam, etc. The data generated was used to provide a basis for the selection of the material and for the determination of the barrier wall thickness. An acceptable balance between the concentrationdriven diffusion of fuel components into the steam and the slight overpressure-driven permeation of the steam into the depleted anode and depleted cathode gas streams was required.

The steam plenum barrier was configured in a series of flow management modules which could be attached to the SOFC bundles and which, when assembled, provided a continuous thin steam plenum across the open end of the cells. Prototypes of these flow management modules were manufactured and the reproducibility was demonstrated. The modules provide a boundary where Low Pressure steam, at slightly higher than module operating pressure, is injected into the plenum and permeates into both the anode and the cathode exhaust plenums. The small steam flow into each of those plenums maintains the effective separation of the stream. Steam addition to the depleted fuel reduces slightly the requirements for reformation re-circulation, and steam added to the exhaust gas is carried out to the atmosphere.

The flow management modules, their assembly and steam generation and delivery systems are the main components and subsystems that are added to the SWPC seal-less generator module to establish and maintain separate anode and cathode streams.

\section{TASK 6 - CONCEPTUAL DESIGN OF THE SOFC AND OTM MODULE(S)}

Based on the above findings within the project, Praxair and SWPC jointly developed a preliminary design for a pilot-scale OTM afterburner for a $10 \mathrm{kWe}$ SOFC. Conceptualizations for a commercialscale OTM afterburner designed to post-combust the residual fuel in the exhaust stream of a $250 \mathrm{kWe}$ SOFC were also developed. At least for initial demonstrations of the technology, Praxair and SWPC agreed that the SOFC and the OTM afterburner would be separate close-coupled modules instead of a single module. Separate modules would provide greater robustness and greater flexibility in designing strategies to facilitate startup, shutdown and transient operation of the SOFC and OTM afterburner units. The afterburner design was modular, so as to be readily scaleable and to reduce fabrication costs and ease maintenance. To address chromium contamination issues, appropriately selected and treated metal alloys were selected. The proprietary Praxair means to prevent OTM degradation due to $\mathrm{SiO}_{2}$-species was also incorporated. A key design challenge was removing the heat generated from the depleted fuel oxidation, while maintaining the OTMs at an acceptable operating temperature. To address this issue, the OTM afterburner contained an integrated heat exchanger to reject heat to steam and/or air. Given a fixed amount of membrane surface area, the ability to manipulate flux is necessary to compensate for turndowns in SOFC capacity during low demand periods, methods to control the flux were devised. Desirable developments to aid in improving future afterburner designs would include greater membrane and seal tolerance for various startup, shutdown and transient schemes, as well as increased OTM resistance to reactor contaminants. 


\section{CONCLUSIONS}

Over 16,700 hours of OTM testing was gained. It was demonstrated that OTMs with no additional membrane catalysts were repeatedly able to completely oxidize depleted fuel from a simulated SOFC anode exhaust, relatively pure and readily sequesterable streams of $\mathrm{CO}_{2}$ were produced as the final streams exiting the experimental OTM reactors at both SWPC and Praxair. Furthermore, it was found that the oxygen flux through the OTMs could be doubled or tripled by proprietary OTM modifications to values that satisfied the economic targets set in this project.

Common reactor contaminants, such as $\mathrm{Cr}$ or $\mathrm{Si}$, were determined to negatively impact OTM performance stability, but various methods of preventing this contamination were devised. Information about OTM membrane and OTM seal reliability over extended periods and through various chemical and thermal shocks and cycles was obtained. SWPC devised a method of separating the anode and cathode exhaust streams exiting the SOFC and these findings were used to develop several conceptual designs for pilot-scale and commercial-scale SOFC/OTM zero emission power generation systems.

Next steps would be to build and operate a pilot-scale test facility to demonstrate the viability of the conceptual design before embarking on a commercial-scale demonstration of the zero-emission power generation technology. Before doing so the following further technology improvements are required. The SWPC steam buffer seal must demonstrate reliable performance and Praxair OTMs must demonstrate improved resistance to rapid thermal and chemical shocks. Both parties are independently working on these issues in ongoing projects within the two organizations. 


\section{BIBLIOGRAPHY}

1. Dale Simbeck - "A Portfolio Selection Approach for Power Plant $\mathrm{CO}_{2}$ Capture, Separation and R\&D Options" ; Presented at the Fourth International Conference on Greenhouse Gas Control Technologies (GHGT-4) - September, 1998.

2. Dale Simbeck - "Gasification in a Carbon-Constrained World"; Presented at the 1998 Gasification Technologies Conference - October, 1998

3. CoGen Europe - "Position Statement - EU Emissions Trading and Combined Heat and Power"; 13 November 2002.

4. Prasad Apte, Shawn Callahan, Cold Isopressing Method, US Patent 63,372,165. April 16, 2002.

5. K. Hilpert et al., "Chromium Vapor Species over Solid Oxide Fuel Cell Interconnect Materials and Their Potential for Degradation Processes", J. Electrochem. Soc., Vol.143, No.11, Nov. 1996, pgs. 3642-47.

6. E. Batawi et al., "New Cost-Effective Ceramic Oxide Phases used as Protective Coatings for Chromium-Based Interconnects", Proc. of the $6^{\text {th }}$ International Symposium on SOFCs, Electrochemical Society Proc. Vol. 99-19, pgs. 767-82.

7. C. Gindorf et al., "Determination of Chromium Vaporization Rates of Different Interconnect Alloys by Transpiration Experiments", Proc. of the $7^{\text {th }}$ International Symposium on SOFCs, Electrochemical Society Proc. Vol. 2001-16, pgs. 793-802.

8. Masakalick et al., "Contaminant Effects in Solid Oxide Fuel Cells", Proceedings of the Joint Contractors Meeting on Advanced Turbine Systems, Fuel Cells \& Coal-Fired Heat, Morgantown, WV, August 1993, pgs. 313-322. 